\title{
Finite Element Model of Shear Behavior of R.C. Flat Slabs Strengthened with Micro-Polypropylene Fibers \\ Khair Al-DeenBsisu ${ }^{1}$, Mu'tasim Abdel-Jaber $^{1}$, AnisShatnawi ${ }^{1}$ \\ ${ }^{1}$ Civil Engineering Department, The University of Jordan, Amman, Jordan
}

\author{
Keywords:Finite Element Analysis, Reinforced Concrete, Flat Slab, Shear, mid-span deflection, \\ Micro-Polypropylene Fibers.
}

Abstract:Experimentalresults offlat slabs cast with concrete enforced with micro-polypropylene fibers showed increased shear strength; this was attributed to increased tensile strength associated with the added fibers. It was also observed that the mid-span deflection at ultimate load increased for concrete strengths less than or equal to $30 \mathrm{MPa}$ butkept the same value for concrete strengths of $40 \mathrm{MPa}$. This paper will apply a finite element model to simulate the behavior of flat slabs and verify that the increased tensile strength connected with the addition of micro-polypropylene fibers to the concrete mixdid in fact contribute to the increased shear resistance of the flat slabs.

\section{Introduction}

In a previous research work carried out by the authors, it was found out that the tensile strength of the concrete enforced with micro-polypropylene fibers increased by $10-15 \%$ and that the total load that caused shear failure in the flat slabs also increased by a similar ratio therefore it was concluded that the increase in the shear capacity was primarily due to the added fibers and increased tensile strength associated with it. To verify this conclusion, the authors developed a finite element model.

Shear failure at a slab-column connection can result in progressive failures of adjacent connections of the same floor, as the load is transferred elsewhere, causing the adjacent connections to become more heavily loaded. Also, the lower floors may fail progressively as they become unable to support the impact of material dropping from above. Hence, caution is clearly needed in shear strength calculations and attention should be given to the low ductility associated with shear strength in order to avoid brittle failure conditions if possible.

Existing design procedures for shear strength, as recommended in the ACI 318 are based primarily on the results of slab-column tests. The actual behavior of the failure region of the cracked slab is extremely complex, primarily because of the combined flexural and diagonal tension crackingand the three-dimensional nature of the problem. The design provisions used are of necessity derived from empirical simplifications of the real behavior.

The use of steel fibers in concrete improves the punching shear resistance allowing higher shear stresses to be transferred through the slab-column connection. In recent years there has been increased interest in the use of fiber-reinforced polymers (FRP) for concrete structures. As one of the new promising technologies in construction, FRP material solves the durability problem due to corrosion of steel reinforcement; hence the use of FRP fibers to replace the steel fibers in the SFRC for resistance of punching shear stresses is a new trend.

In a study by Gaston Kruger, et al (1998), six large square slabs were tested with a constant value of concrete compressive strength. Results indicated a linear diminution of the punching shear with increased eccentricity. Later results of tests were compared against six different codes in which the British Standards gave the best estimate of the punching strength with an eccentricity. Ronaldo Gomes 
and Paul Regan in (1999) proposed a theoretical model for analyzing the punching resistance of reinforced concrete for flat slabs with shear reinforcement of concentric loading.

Another study by Tuan Ngo (2001) carried a 29 test results taken from four different researchers consisted of circular and square slabs with a variable concrete compressive strength. Results showed that the use of high strength concrete improves the punching shear resistance allowing higher forces to be transferred through the slab-column connection. In (2004) PovilasVainiunas, et alcarried a finite element modeling analysis study showing good agreement with their eight floor slabs tested.

L. Nguyen-Minh et al (2012), studied the behavior and capacity of steel fiber reinforced concrete flat slabs under punching shear force and investigated the effect of steel fibers amount on punching shear cracking behavior and resistance of the slabs by testing twelve small scale flat slabs of different dimensions.

L.F. Maya et al (2012), presented a mechanical model for predicting the punching strength and behavior of concrete slabs with steel fibers, the proposed approach was compared to 140 slab-column connection tests reported in the literature, their model exhibited good agreement with the test results and properly represented the influence of steel fibers on the punching strength of FRC slab-column connections.

Fernández and Muttoni (2009), applied the critical shear crack theory to punching of reinforced concrete slabs with transverse reinforcement and concluded that the contribution of concrete to the punching shear strength of flat slabs is not constant and that the contribution of concrete to the punching shear strength is reduced for large rotations of the slab.

Cheng and Parra-Montesinos (2010), conducted a series of tests on slabs under monotonically increased concentrated load. Four different types of FRCs (or fiber reinforced mortar) and two slab tensile reinforcement ratios were evaluated. The conclusions were that the addition of fibers led to an increase in slab punching shear strength and/or deformation capacity, this increase in punching shear strength due to the use of FRC may lead to a change in failure mode from punching shear failure to flexural yielding. Test results showed that FRC only in the connection region over two slab thicknesses from each column stub face was sufficient to increase punching shear resistance in the test specimens.

\section{Material Properties:}

High performance micro polypropylene fibers meeting the requirements of ASTM C111.6 and having a tensile strength of minimum $300 \mathrm{~N} / \mathrm{m}^{2}$ were used (FOSROC - PPF) the properties of which is listed in Table 1. 
Table 1. Mechanical properties of the micro-polypropylene fibers

\begin{tabular}{|l|l|}
\hline Form & Virgin Polypropylene fibers \\
\hline Specific gravity & $0.91 \mathrm{~g} / \mathrm{cm}^{3}$ \\
\hline Fiber thickness & 18 and 30 microns \\
\hline Young's Modulus & $5500-7000 \mathrm{MPa}$ \\
\hline Tensile Strength & $350 \mathrm{~N} / \mathrm{mm}^{2}$ \\
\hline Melting Point & $160^{\circ} \mathrm{C}$ \\
\hline Alkali content & Nil \\
\hline Sulfate content & Nil \\
\hline Air Entrainment & $\begin{array}{l}\text { Air content of concrete will not be } \\
\text { significantly increased }\end{array}$ \\
\hline
\end{tabular}

The concrete cylinders were tested for tensile strength and the tensile strength of concrete showed an increase of about $10 \%$ to $12 \%$ as tabulated in Table 2 .

Table 2. Tensile Strength of Concrete with Micro-Polypropylene Fibers

\begin{tabular}{|c|c|c|c|}
\hline $\begin{array}{c}\text { Concrete Nominal } \\
\text { Compressive } \\
\begin{array}{c}\text { Strength } \\
f_{\mathrm{c}}^{\prime}(\mathrm{MPa})\end{array}\end{array}$ & $\begin{array}{c}\text { Concrete } \\
\text { Experimental } \\
\text { Tensile Strength } \\
f_{\mathrm{c}}^{\prime}(\mathrm{MPa})\end{array}$ & $\begin{array}{c}\text { Micro-Polypropylene } \\
\text { Fiber Content \% }\end{array}$ & $\begin{array}{c}\text { Concrete } \\
\text { Experimental } \\
\text { Tensile Strength } \\
f_{\mathrm{r}}^{\prime}(\mathrm{MPa})\end{array}$ \\
\hline \multirow{3}{*}{20} & 20.6 & 6 & 3.05 \\
\cline { 2 - 4 } & 19.8 & 7.5 & 3.32 \\
\cline { 2 - 4 } & 20.2 & 9 & 3.61 \\
\cline { 2 - 4 } & 29.25 & 6 & 3.75 \\
\cline { 2 - 4 } & 29.8 & 7.5 & 3.88 \\
\hline \multirow{3}{*}{40} & 30.6 & 9 & 3.96 \\
\cline { 2 - 4 } & 40.2 & 6 & 4.35 \\
\cline { 2 - 4 } & 39.7 & 7.5 & 4.52 \\
\hline
\end{tabular}

\section{The Finite Element Model:}

A finite element model was created as shown in Figure 1 with the same dimensions of the experimental specimens and material properties as listed above, and then the model was subjected to loadinggradually until ultimate load was reached.

Concrete is a quazi-brittle material that is very weak in tension; tensile stresses are usuallyresisted by the reinforcing steel bars. In concrete elements where there is no reinforcement in the near vicinity, a post-failure model characterized by the fracture energy defined by was used as a material parameter required to open a unit area of crack, termed the fracture energy. This analogy of concrete behavior utilizes theconcept of a stress-displacement behavior rather than stress-strain one. When the stresses 
causethe concrete to crack across some section the elements are pulled apart so that most of the stress isdissipated and the undamaged elastic strain is small, the crack length will be determined by theopening of the crack. Alternatively, the fracture energycan be specified directly as a materialproperty that assumes a linear loss of strength.

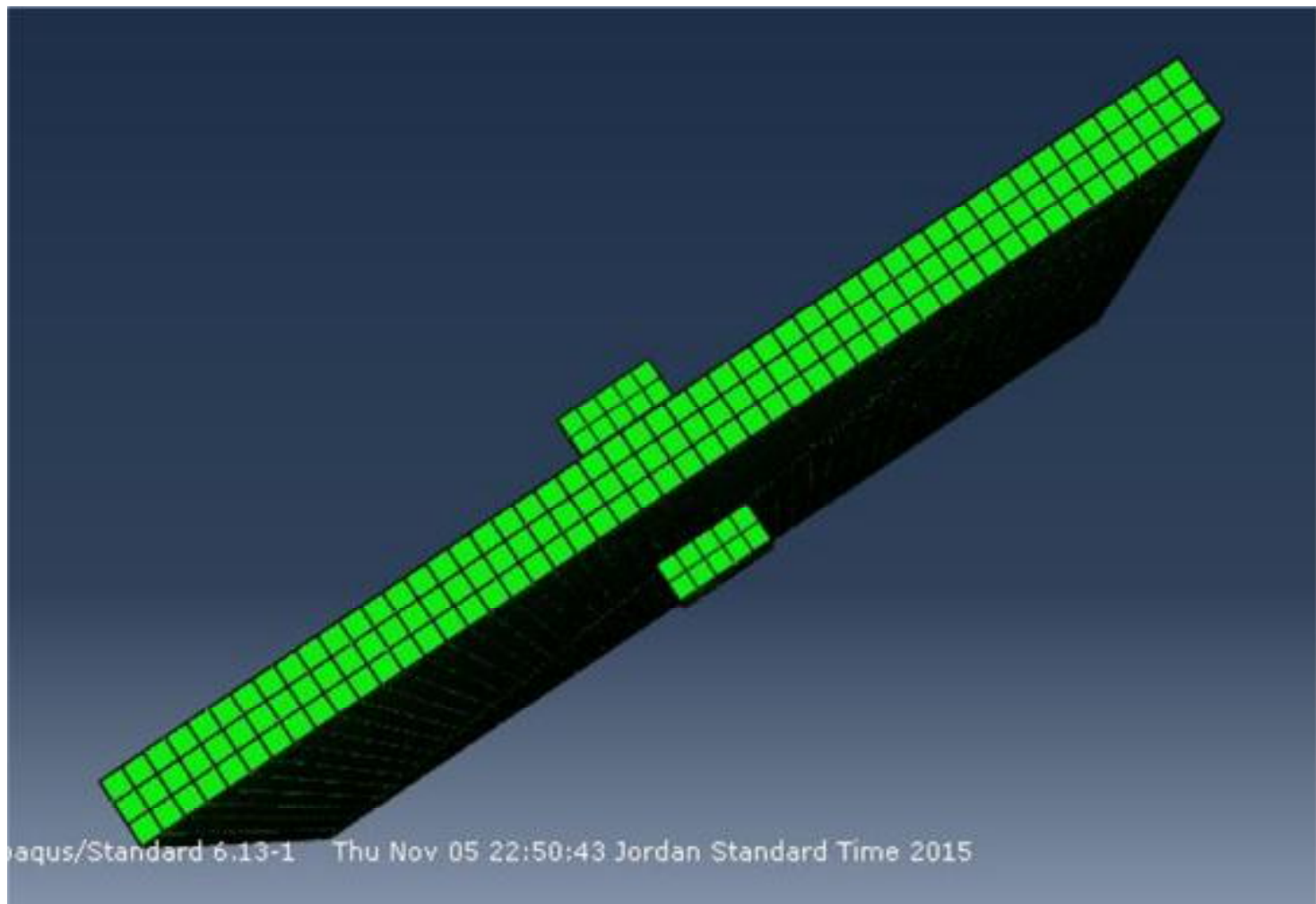

Figure 1. The Finite Element Model

\section{Results and Discussion}

The finite element model was loaded until failure due to shear occurred in the model as shown in Figure 2, ultimate loading, stresses and deflection at mid-span were compare with the experimentally obtained results as shown in table 3 .

The finite element model utilizing the experimentally attained concrete tensile strength showed a large degree of conformity to the experimental results, as shown in Figure 3. 


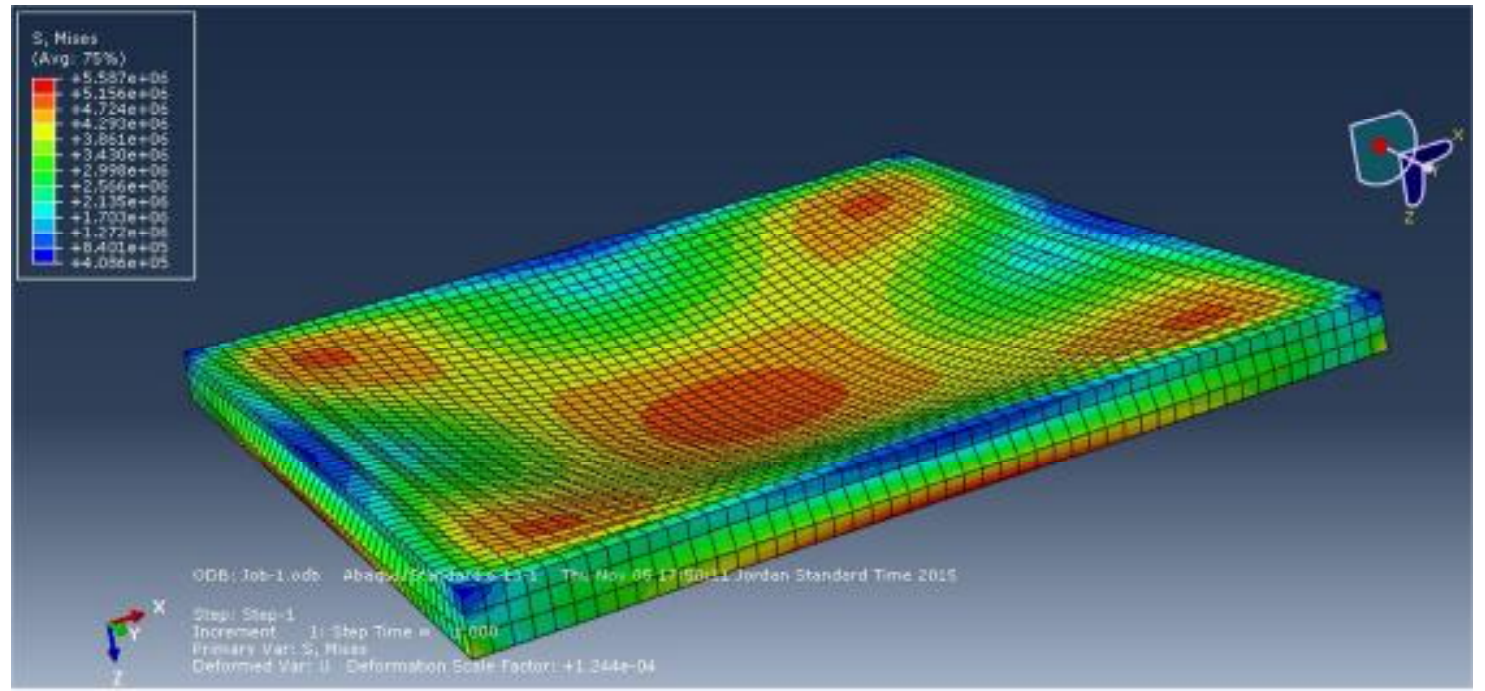

Figure 2. Maximum stresses after loading the model
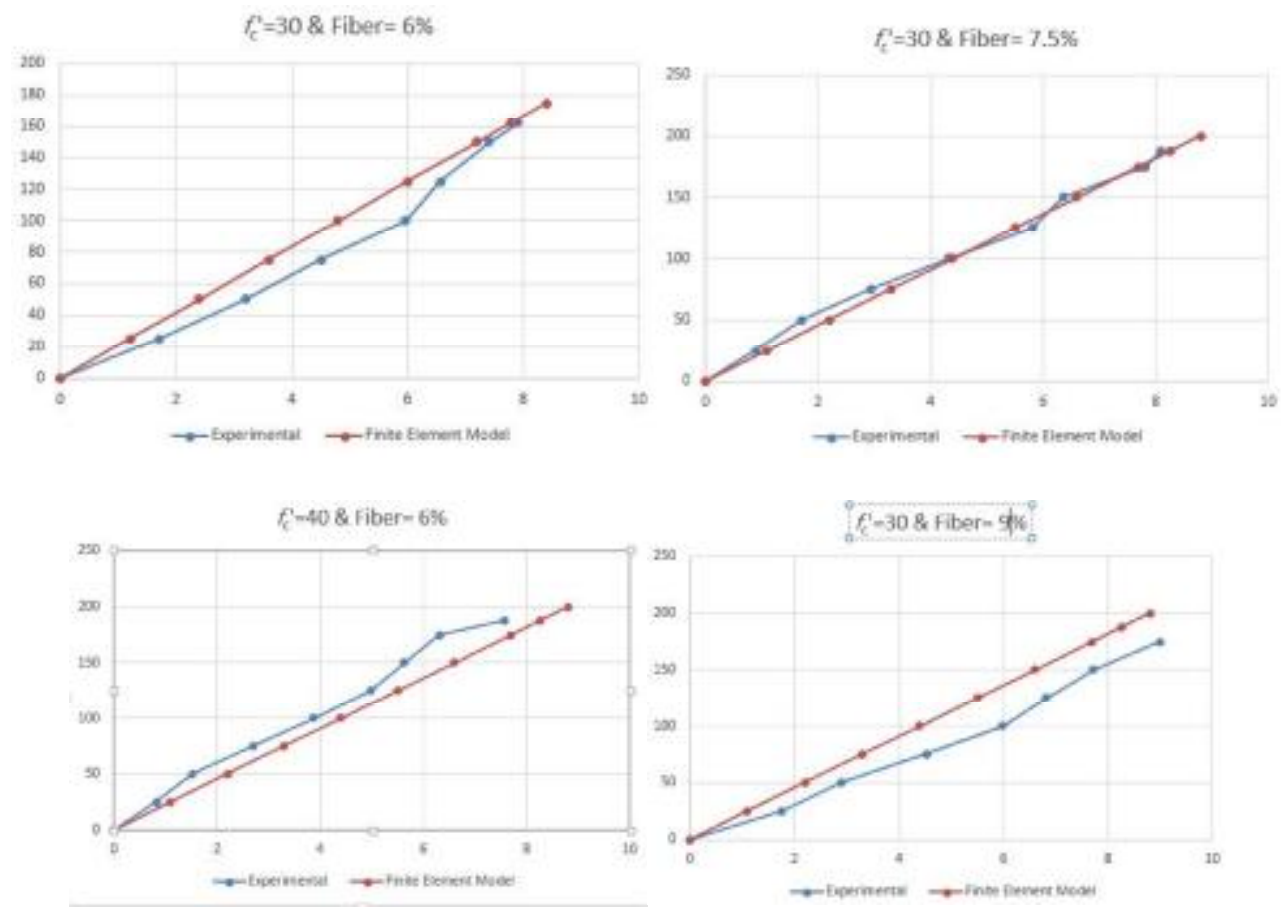

Figure 3. Sample results showing experimental VS FEM

\section{Conclusions}

It can be concluded from the above figures that adding micro-polypropylene fibers to the concrete mix will give it extra tensile strength that will contribute to the shear resistance of the flat slabs both in punching and one-way shear. The finite element model crack propagation was compared to the experimental cracks developed and it showed large similarity.

From this result it is understood that the punching shear resistance and deflection at failure of flat slabs using concrete with $f_{\mathrm{c}}$ ' $\leq 30 \mathrm{MPa}$ is enhanced when using the micro-polypropylene fibers with different ratioswhile the flat slab made using concrete with $f_{\mathrm{c}}$ ' $\geq 30 \mathrm{MPa}$ and micro-polypropylene fibers will 
only enhance the shear resistance but will not increase the deflection at failure. This means that the tensile strength of the concrete has been enhanced, i.e. the fibers will resist more tensile forces in the shear zone.

\section{Acknowledgments}

The authors would like to thank the deanship of academic research in The University of Jordan for their financial support to perform this research.

\section{References}

[1] ACI 318-2005, Building Code Requirement for Reinforced Concrete. American Concrete Institute, Detroit.

[2] BS 8110-2002, Code of the Practice for Design and Construction. British Standards, Structural use of Concrete, Part 1.

[3] Cheng. Y, Gustavo J. Parra-Montesinos. Evaluation of Steel Fiber Reinforcement for Punching Shear Resistance in Slab-Column Connections- Part I: Monotonically Increased Load. ACI Structural Journal. Feb 2010. Pp. 101-109.

[4] D. Tuan Ngo, Punching Shear Resistance of High-Strength Concrete Slabs. Electronic Journal of Structural Engineering, 1, 2001, pp 52-59.

[5] Fernández Ruiz M., Muttoni A. Applications of the Critical Shear Crack theory to punching of R/C Slabs with transverse reinforcement. ACI Structural Journal, Vol. 10, 6 No. 4. 2009, pp. 485-495.

[6] Gaston Kruger, Olivier Burdet and Renaud Favre, Punching Tests on RC Flat Slabs with Eccentric loading. $2^{\text {nd }}$ IntPh.D Symposium in Civil Engineering 1998, Budapest.

[7] Ibrahim M. Metwalyy, Mohamed S. Issa and Sameh A. El-Betar. Punching Shear Resistance of Normal and High Strength Reinforced Concrete Flat Slabs. Civil Engineering Research magazine. Vol. 30, No. 3. Oct. 2008, pp 983-1004.

[8] Long Nguyen-Minh, Marian Rovnak and Toan Tran Quoc. Punching Shear Capacity of Interior SFRC Slab Column Connections. Journal of Structural Engineering, Vol. 138, Issue 5 May 2012.

[9] Marzouk, H., and Hussein, A.,Experimental Investigation on the Behavior of

[10] High-Strength Concrete Slabs, ACI Structural Journal, Vol. 88, No. 6, Nov.-

[11]Dec. 1991, pp. 701-713.

[12] Maya Duque, Fernandez Ruiz, M. Muttoni and Foster S. J. Punching Shear Strength of Steel Fiber Reinforced Concrete Slabs. Engineering Structures, Vol. 40, UK 2012, pp.93-94.

[13] M. Cheng and Parra-Montesions. Evaluation of Steel fiber Reinforcement for punching Shear Resistance in Slab-Column Connections. ACI Structural journal, 107-1. Jan 2010, pp 101-109.

[14]Nobari, H. F. and Ejlaly, R.,Punching Shear Resistance of High-Strength

[15] Concrete Slabs. Asian Journal of Civil Engineering,Building and Housing,

[16] Vol. 4, No. 1, 2003, pp. 55-63.

[17] PovilasVainiunas, VladimirasPopovas and Andrej Jarmolajev, Non Linear FEM Analysis of RC Floor Slab-to-Column Joint Connection. Theoritical Foundation of Civil Engineering, Warsaw 2004, pp 527-538.

[18]Ronaldo B. Gomes and Paul E. Regan, Punching Resistance of RC Flat Slabs with Shear Reinforcement. Journal of Structural Engineering, June 1999, pp 684-692. 